\title{
Methylammonium Lead Bromide Perovskite Battery Anodes Reversibly Host High Li-ion Concentrations
}

\author{
Nuria Vicente and Germà Garcia-Belmonte* \\ Institute of Advanced Materials (INAM), Universitat Jaume I, 12006 Castelló, Spain
}

Corresponding author's e-mail: garciag@uji.es (G. G.-B)

\begin{abstract}
Ions migrate through the hybrid halide perovskite lattice allowing for a variety of electrochemical applications as perovskite-based electrodes for batteries. It is still unknown how extrinsic defects as lithium-ions interact with the hybrid perovskite structure during the charging process. It is shown here that $\mathrm{Li}^{+}$intake/release proceeds by topotactic insertion into the hybrid perovskite host, without drastic structural alterations or rearrangement. Even the perovskite electronic band structure remains basically unaltered upon cycling. The occurrence of conversion or alloying reactions producing metallic lead is discarded. Stable specific capacity $\approx 200 \mathrm{~mA} \mathrm{~h} \mathrm{~g}^{-1}$ is delivered which entails outstanding Li-ion concentration, $x$ in $\mathrm{Li}_{x} \mathrm{CH}_{3} \mathrm{NH}_{3} \mathrm{PbBr}_{3}$, approaching 3. Slight distortions of the perovskite lattice upon cycling explain the highly-reversible $\mathrm{Li}^{+}$ intercalation reaction that also exhibits an excellent rate capability.
\end{abstract}

\section{TOC figure}

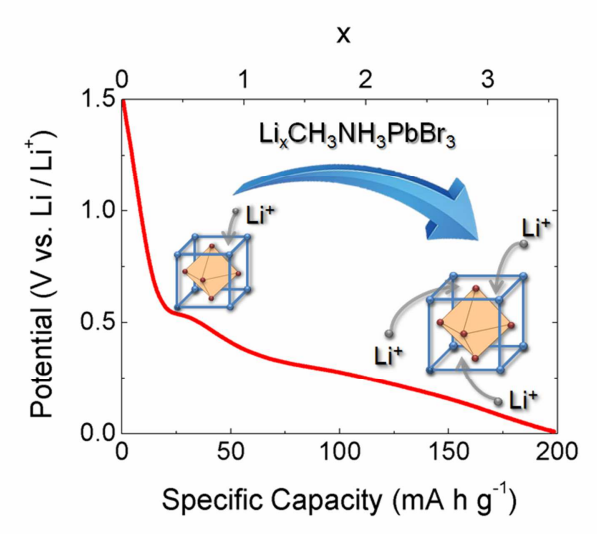


Hybrid perovskites have emerged as a family of multifunctional materials with applications in photovoltaics, ${ }^{1-2}$ optoelectronics, ${ }^{3-5}$ lasers, ${ }^{6-7}$ and electrochromism. ${ }^{8}$ Besides the interesting electronic and photonic properties exhibited by hybrid perovskites, ionic migration allows for a variety of application in electrochemical devices. Ion transport within the lattice of perovskite compounds have applications in solid-oxide fuel cells and oxygen permeation membranes. ${ }^{9-10}$ It is also known that hybrid perovskites behave as charge storage materials for lithium-ion battery anodes. ${ }^{11}$ In addition, native defects in hybrid lead halide perovskite materials are able to migrate within the perovskite structure because of the soft character of the compounds. ${ }^{12}$ Despite the relevance extrinsic ion reaction with hybrids perovskites might have on their potential use in electrochemical devices, only a few works have addressed that issue. ${ }^{11}$ How lithium-ions interact with the hybrid perovskite structure during the charging process is still an open question. ${ }^{13}$ It is revealed here that perovskite-based electrodes exhibit high stability upon electrochemical cycling without severe distortions of the crystal structure. This fact indicates a topotactic intercalation for $\mathrm{Li}^{+}$storage into the perovskite host, without drastic structural alterations or rearrangement. Lithiation proceeds in such a way that several Li-ions are hosted within the same unit cell of the crystal lattice $\left(\mathrm{Li}_{x} \mathrm{CH}_{3} \mathrm{NH}_{3} \mathrm{PbBr}_{3}\right)$ with $x$ approaching 3. Moreover, the occurrence of conversion or alloying reactions producing metallic lead can be discarded.

In the present work, the hybrid perovskite $\mathrm{CH}_{3} \mathrm{NH}_{3} \mathrm{PbBr}_{3}$ has been utilized as active material for the anode electrodes. Its interest in energy storage is related to their $3 \mathrm{D}$ framework of corner-connected $\mathrm{MX}_{6}(\mathrm{M}=\mathrm{Pb}, \mathrm{X}=\mathrm{Br})$ octahedrons with organic methylammonium cations located between them (Figure 1d). The hybrid halide perovskite $\mathrm{AMX}_{3}$ can be then regarded as a compact structure in which the dimensionality of $\mathrm{Li}^{+}$transport is $3 \mathrm{D}$, similarly to that occurring for spinels such as $\mathrm{LiMn}_{2} \mathrm{O}_{4}$ in contrast to low-dimension insertion compounds. We present here promising preliminary results and progress into the understanding of the electrochemical charging of nanostructured lead halide perovskite materials, which exhibit rather stable specific capacity $\approx 200 \mathrm{~mA} \mathrm{~h} \mathrm{~g}^{-1}$ with an excellent reversibility. Rate capability between $1 \mathrm{C}$ and $0.25 \mathrm{C}$ charging rates does not significantly change, enabling for high-power performance. Although exhibiting similar electrochemical response, the issue of the underlying intercalation mechanism is not addressed by the previous works on perovskite-based anodes. $^{11}$

Starting material were synthesized by slow evaporation of N, N-dimethylformamide (DMF, Sigma-Aldrich) in a solution containing stoichiometric amounts of lead bromide $\left(\mathrm{PbBr}_{2}, \mathrm{TCI}\right)$ and methylammonium bromide $\left(\mathrm{CH}_{3} \mathrm{NH}_{3} \mathrm{Br},>98 \% \mathrm{TCI}\right) 1 \mathrm{M}$ in DMF. First $\mathrm{PbBr}_{2}$ and $\mathrm{CH}_{3} \mathrm{NH}_{3} \mathrm{Br}$ were dissolved in $\mathrm{DMF}$, and then the solution was heat up $90{ }^{\circ} \mathrm{C}$ in magnetic stirring in a close bottle for 12 hours. Solid precipitated is orange color at the end of the reaction. The solution was stirred with a spatula to ensure the evaporation process of trapped solvent. Finally, it was taken out and cooled down to room temperature naturally. XRD to confirm the pure perovskite crystallographic were 
measured using Bruker AXS-D4 Endeavor Advance X-ray diffractometer using $\mathrm{Cu} \mathrm{K \alpha}$, wavelength $\lambda=1.5406 \AA$.

To fabricate the working electrode, the homogeneous slurry was prepared by mixing $\mathrm{CH}_{3} \mathrm{NH}_{3} \mathrm{PbBr}_{3}$, conductive carbon black (Super $\mathrm{P}$ ) and poly(vinylidenedifluoride) binder (PVDF, Sigma-Aldrich) with a 80:10:10 weight ratio, respectively, by using Nmethyl-2-pyrrolidone (NMP) as solvent. The slurry was coated on a copper foil by doctor blade and dried at $100^{\circ} \mathrm{C}$ overnight. Composite electrodes slices with a diameter of $10 \mathrm{~mm}$ were cut and used as working electrodes for structural investigation and electrochemical analysis.

To investigate the lithium storage performance of the anode under study, a twoelectrode Swagelok cell-type was used. Li metal foil was used as the counter and reference electrode and an electrolyte-soaked, microporous monolayer membrane (Celgard 2500) was employed as separator. The electrolyte is $1 \mathrm{M}$ of hexafluorophosphate lithium slat $\left(\mathrm{LiPF}_{6}\right.$, Sigma-Aldrich) dissolved in ethylene carbonate, ethyl-methyl carbonate and dimethyl carbonate (EC:EMC:DMC, SigmaAldrich) with 1:1:1 v/v. Cell assembly was carried out in a $\mathrm{N}_{2}$ filled glovebox. For electrochemical characterization, a PGSTAT-30 potentiostat from AUTOLAB equipped with an impedance module was employed. Cyclic voltammetry (CV) was performed in the voltage range from 0.01 to $2.00 \mathrm{~V}$ with a rate of $5 \mathrm{mV} \mathrm{s}^{-1}$. The constant current charge and discharge profiles of the battery in the voltage range from $0.01 \mathrm{~V}$ to $1.80 \mathrm{~V}$ at different rates of 50,100 and $200 \mathrm{~mA} \mathrm{~g}^{-1}$. All the data are normalized to the load $\mathrm{CH}_{3} \mathrm{NH}_{3} \mathrm{PbBr}_{3}$ mass.

It is shown in Figure 1a XRD patterns of $\mathrm{CH}_{3} \mathrm{NH}_{3} \mathrm{PbBr}_{3}$ powders fabricated by means of the procedure previously described. It can be indexed as a cubic perovskite structure with $a=5.9394 \AA$ (space group $=\mathrm{Pm}-3 \mathrm{~m}$ ). Diffraction peaks are assigned similarly to those appearing in previous publications. ${ }^{16}$ It is shown in Figure 1S (Supporting Information) how diffraction peak positions remain unaltered upon lithiationdelithiation, which informs on the integrity of the structure. Recent XRD analyses on $\mathrm{CsPbBr}_{3}$ films after electrochemical doping reveal slight increase of the lattice constant as a consequence of lithiation, signaling negligible structural variations. ${ }^{8}$ Figure $1 \mathrm{~b}$ and Figure 1c show SEM images of pristine $\mathrm{CH}_{3} \mathrm{NH}_{3} \mathrm{PbBr}_{3}$ anodes. Most particles are regular and uniform with average size around $65 \mathrm{~nm}$. Electrode surface is uniform although some pinholes are observed within which secondary particle agglomeration occurs. It is noted here that our synthesis produces nanometer-sized particles different from those reported in previous work, ${ }^{11}$ which shows the formation of large micrometersized structures by hydrothermal methods.

With the aim of investigating the chemical stability of the lead bromide perovskite upon cycling, a detailed ex-situ XPS analysis at different charging states during the first charge-discharge cycle is shown in Figure 1e and Figure 1f. Samples were washed out by anhydrous dimethyl carbonate (DMC) solvent several times, and dried in a vacuum chamber at $60^{\circ} \mathrm{C}$ for $2 \mathrm{~h}$ previous XPS analysis. ${ }^{14}$ Here two elements are analyzed: 
bromine and lead. XPS spectra for different samples were studied using a C peak at $285.0 \mathrm{eV}$ as reference, which allows identifying the valence states of the elements in pristine and cycled electrodes. In all studied electrodes, the XPS spectrum of lead appears as $\mathrm{Pb}^{+2}(\mathrm{~Pb} 4 \mathrm{f})$ in Figure 1e, and exhibits two peaks attributed to $\mathrm{Pb} 4 \mathrm{f}_{7 / 2}$ and $\mathrm{Pb}$ $4 \mathrm{f}_{5 / 2}$ levels at binding energies (BE) of $138.7 \mathrm{eV}$ and $143.6 \mathrm{eV}$, respectively. This is in full agreement to values reported previously. ${ }^{15-16}$ In no case it is observed any signal corresponding to metallic lead $\left(\mathrm{Pb}^{0}\right)$. A recent analysis on $\mathrm{CsPbBr}_{3}$ large single crystals has detected the presence of $\mathrm{Pb}^{0}$ by electrochemical lithiation but using much wider $(-5$ $\mathrm{V}<V<5 \mathrm{~V}$ ) potential windows. ${ }^{8}$ Our results also indicate that $\mathrm{Pb}$ does not react to form any kind of Li-Pb alloy. It should be noted that the increase in binding energy of the $\mathrm{Pb}$ 4f lines $(0.3 \mathrm{eV})$ upon discharge is hardly attributed to a change in the Pb oxidation state. After delithiation, XPS peaks recover in part the initial position. Small shifts can be related to a redistribution of bond electron charges. ${ }^{17}$ It has been recently reported that ionic accumulation in perovskite compounds produces reversible lattice swell/shrink of approximately $4.4 \% .^{18}$ It is then not surprising that $\mathrm{Pb}$ bonds will undergo slight variations upon $\mathrm{Li}^{+}$intake and release.

Spectra of $\mathrm{Br} 3 \mathrm{p}$ shows the $\mathrm{Br} 3 \mathrm{p}_{3 / 2}$ level that has a binding energy of $182.4 \mathrm{eV}$ and $\mathrm{Br} 3 \mathrm{p}_{1 / 2}$ level of $189.1 \mathrm{eV}$ (Figure 1f), similar to those observed earlier. Analysis of C 1s spectra present two peaks (see Figure 2S, Supporting Information), at $285.0 \mathrm{eV}$ and $290.0 \mathrm{eV}$, respectively. The peak at higher energy can be assigned to $\mathrm{Li}_{2} \mathrm{CO}_{3}$ residuals, which could be formed because of electrolyte decomposition upon cycling. Finally, in the case of $\mathrm{O} 1 \mathrm{~s}$, the XPS bands appear at $531.8 \mathrm{eV}$ and $532.9 \mathrm{eV}$, which is consistent with the presence of $\mathrm{Li}_{2} \mathrm{CO}_{3}$ as a cycling byproduct. Consequently, our analysis clearly confirms the stable presence $\mathrm{CH}_{3} \mathrm{NH}_{3} \mathrm{PbBr}_{3}$ after electrochemical cycling, indicating that successive lithium-ion intake and release does not cause severe distortions into the perovskite crystallographic structure. Moreover, also the electronic structure remains basically unaltered. It is already known that $\left[\mathrm{PbBr}_{6}\right]^{4-}$ clusters largely dictate the electronic structure near the band edge. ${ }^{19}$ Our findings point to the permanent presence of $\mathrm{PbBr}_{6}$ building blocks upon lithiation and, consequently, continuity of the basic band structure. A detailed analysis of the band positions at different intercalation states would help us on this concern. ${ }^{20}$ Electronic changes affecting the A-site organic cation cannot be discarded. These last facts signal the occurrence of a topotactic $\mathrm{Li}^{+}$insertion into the perovskite lattice, without severe alterations of crystal or main band structure, and unlikely occurrence of conversion or alloying reactions. 

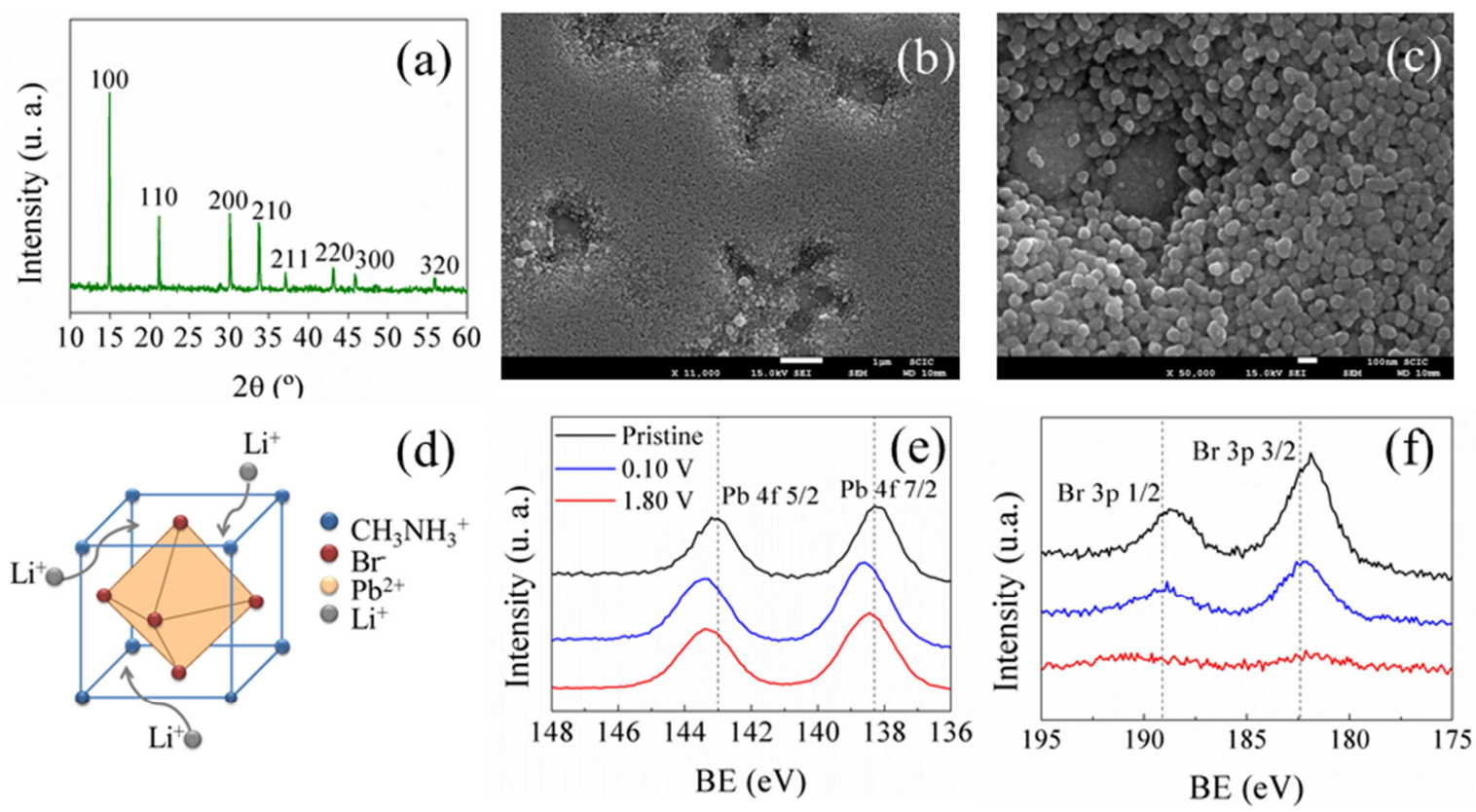

Figure 1. Structural analysis of lead bromide perovskite. (a) X-ray diffraction patterns of $\mathrm{CH}_{3} \mathrm{NH}_{3} \mathrm{PbBr}_{3}$ powder, which can be indexed as cubic perovskite (space group = Pm-3m, $a=5.9394 \AA$ A. SEM morphology images of the $\mathrm{CH}_{3} \mathrm{NH}_{3} \mathrm{PbBr}_{3}$ electrodes. Scale bar: (b) $1 \mu \mathrm{m}$; (c) $100 \mathrm{~nm}$. Average perovskite particle size $65 \mathrm{~nm}$. (d) Schematic crystal structure of organometal halide perovskite $\mathrm{CH}_{3} \mathrm{NH}_{3} \mathrm{PbBr}_{3}$ indicating multiple Li-ion intake (e) $\mathrm{Pb} 4 \mathrm{f}$ and (f) $\mathrm{Br} 3 \mathrm{~d}$ core level XPS signal of $\mathrm{CH}_{3} \mathrm{NH}_{3} \mathrm{PbBr}_{3}$ anodes at different states: pristine, $0.10 \mathrm{~V}$ (discharge), and $1.80 \mathrm{~V}$ (subsequent charge).

For testing electrochemical response, perovskite-based anodes were monitored by cyclic voltammetry. Figure $2 \mathrm{a}$ shows the first four cycles that do not change significantly through continuous cycling. It confirms the good reversibility of the electrode material. The redox peaks related to $\mathrm{Li}^{+}$insertion is observed at $0.49 \mathrm{~V}$ and $0.27 \mathrm{~V}$ vs. $\mathrm{Li} / \mathrm{Li}^{+}$, and the extraction from the matrix produces two peaks in the delithiation current at $0.65 \mathrm{~V}$ and $0.75 \mathrm{~V}$ vs. $\mathrm{Li} / \mathrm{Li}^{+}$. The width of the peaks and the separation between them are related to the kinetic limitations (resistances) present in the electrode. The anodic and cathodic peaks relate to the charge-discharge voltage plateaus in the galvanostatic profiles (Figure 2c). As inferred from previous XPS analysis, ion intake proceeds without severe structural changes and explains the observed redox response. In order to check if the lead precursor shows electrochemical activity, $\mathrm{PbBr}_{2}$ electrodes are investigated to compare them with $\mathrm{CH}_{3} \mathrm{NH}_{3} \mathrm{PbBr}_{3}$ electrodes (Figure 2a). 
As observed, the redox response does take place into the perovskite lattice and not within its precursors.

Galvanostatic charge-discharge test of electrodes within the voltage range $0.01 \mathrm{~V}$ to $1.80 \mathrm{~V} \mathrm{vs} \mathrm{Li} / \mathrm{Li}^{+}$at different charging current rate of 50,100 and $200 \mathrm{~mA} \mathrm{~g}^{-1}$ can be seen in Figure $2 \mathrm{~b}$. A gradual fading is seen during the first several cycles. The charge and discharge specific capacities situate around $200 \mathrm{~mA} \mathrm{~h} \mathrm{~g}^{-1}$, with the Coulombic efficiency above $99 \%$, till around 20 cycles. These specific capacity values are higher than the theoretical capacity of commercial $\mathrm{Li}_{4} \mathrm{Ti}_{5} \mathrm{O}_{12}, 175.5 \mathrm{~mA} \mathrm{~h} \mathrm{~g}$. From known values of lattice constant $(a=5.93 \AA)$, density $\left(3.83 \mathrm{~g} \mathrm{~cm}^{-3}\right)$, and molecular weight (478.92 $\mathrm{g} \mathrm{mol}^{-1}$ ) of $\mathrm{CH}_{3} \mathrm{NH}_{3} \mathrm{PbBr}_{3}{ }^{21}$ one can readily estimate the reached $\mathrm{Li}$ concentration per unit cell, $x$ in $\mathrm{Li}_{x} \mathrm{CH}_{3} \mathrm{NH}_{3} \mathrm{PbBr}_{3}$. As observed in Figure 2c, lithiation attains molar contents as high as $x=3$. This is certainly an outstanding charging value in comparison to other intercalation compounds that signals multiple unit cell $\mathrm{Li}^{+}$intake. It is remarkable that the first voltage plateau at $0.5 \mathrm{~V}$ is reached for insertion concentrations approaching $x=1$ (Figure 2c). This can be interpreted in terms of a full charging, with each unit cell hosting one Li-ion, before subsequent multiple insertion. Provided the attained high $\mathrm{Li}^{+}$concentration, one can expect electronic density values approaching $10^{22} \mathrm{~cm}^{-3}$. This is uncommon for intercalation compounds and might indicate the intrinsic ability of hybrid perovskites of holding huge amounts of conduction band electrons without changes of the electronic structure. Recent papers have pointed out the occurrence of electronic accumulation zones at perovskite interfaces, which also imply large electronic density values. ${ }^{22}$

Higher capacity is reached in the first discharge curve $\left(\sim 600 \mathrm{~mA} \mathrm{~h} \mathrm{~g}^{-1}\right)$, which presumably correspond to the formation of a solid electrolyte interface (SEI) layer. On the other hand, cyclability has been evaluated at $50 \mathrm{~mA} \mathrm{~g}^{-1}$ after initial 10 cycles (Figure 2 c). Discharge profiles delivers specific capacities decreasing from $\approx 265 \mathrm{~mA} \mathrm{~h} \mathrm{~g}^{-1}$ to $\approx 165 \mathrm{~mA} \mathrm{~h} \mathrm{~g}^{-1}$. After 10 days of relax, additional 15 cycles shows diminution in specific capacity from 150 down to $100 \mathrm{~mA} \mathrm{~h} \mathrm{~g}^{-1}$ (Figure 2c). As observed in Figure $2 \mathrm{~b}$ the rate capability do not significantly change for cycling performed between $1 \mathrm{C}$ and $0.25 \mathrm{C}$ rate charging currents (assuming 1C equaling $200 \mathrm{~mA} \mathrm{~g}^{-1}$ ). This fact signals the occurrence of fast $\mathrm{Li}^{+}$intake and release presumably produced by a large value of the ionic diffusion coefficient in the lead bromide perovskite lattice. 

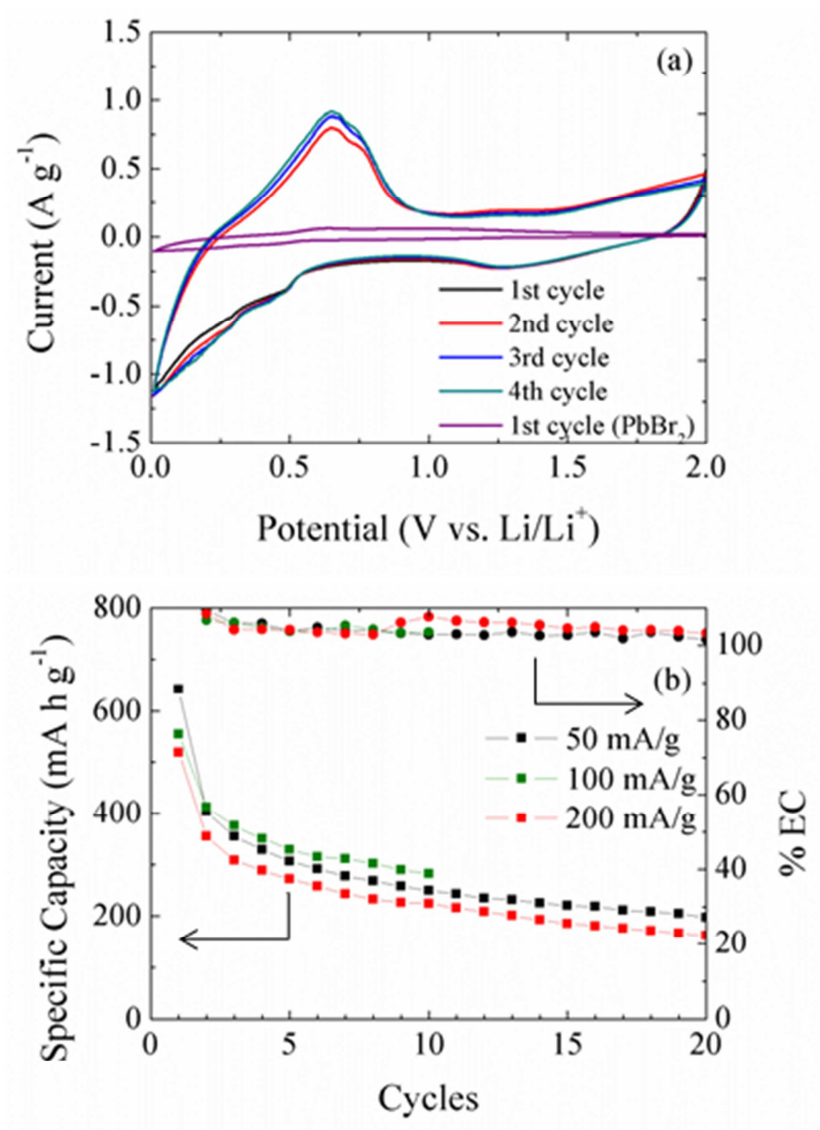

$\mathrm{x}$

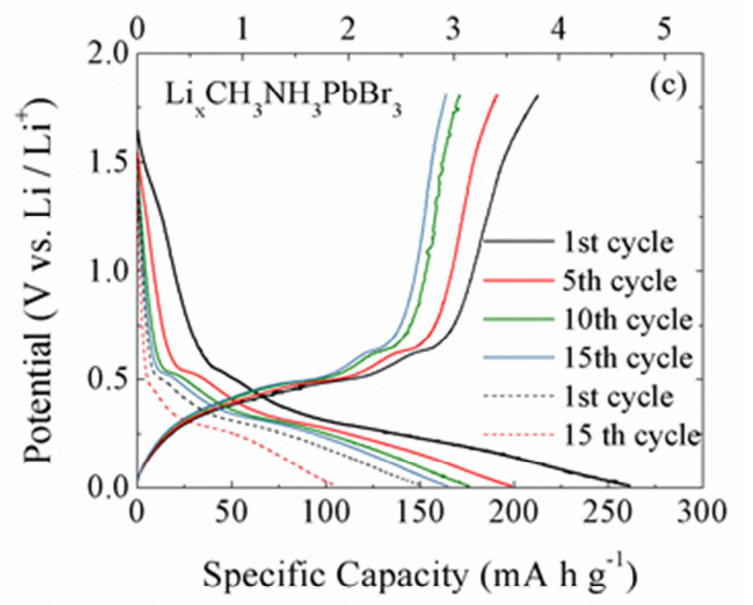

Figure 2. Battery electrochemical characterization. (a) Comparative cyclic voltammograms of $\mathrm{CH} 3 \mathrm{NH} 3 \mathrm{PbBr} 3$ electrodes for the first four cycles in comparison to $\mathrm{PbBr} 2$ electrode. (b) Specific capacity and Coulombic efficiency of $\mathrm{CH}_{3} \mathrm{NH}_{3} \mathrm{PbBr}_{3}$ anodes corresponding to initial 20 cycles at different charging current densities: 50, 100 and $200 \mathrm{~mA} \mathrm{~g}^{-1}$. (c) Discharge/charge voltage profiles as a function of specific capacity and corresponding Li-ion content after 10 initial cycles (continuous lines), and after 10 
days relax performing additional 15 cycles (dashed line).

In summary, $\mathrm{CH}_{3} \mathrm{NH}_{3} \mathrm{PbBr}_{3}$ is reported to be a promising anode material. Reversible $\mathrm{Li}^{+}$ storage occurs by ion intercalation into the host electrode without severe distortion of the $\mathrm{CH}_{3} \mathrm{NH}_{3} \mathrm{PbBr}_{3}$ lattice. Even the basic band structure remains basically unaltered for the potential window of interest. Long-term specific capacity attains significant values approaching $200 \mathrm{~mA} \mathrm{~h} \mathrm{~g}^{-1}$. Lithiation reaches molar contents as high as $x=3$ (moles of lithium per mole of methylammonium), an outstanding value in comparison to other intercalation compounds. $\mathrm{CH}_{3} \mathrm{NH}_{3} \mathrm{PbBr}_{3}$ gathers then two main advantages: (i) it allows for high insertion concentrations with $x>>1$, and simultaneously (ii) it exhibits small structural distortions (topotactic intercalation). Importantly, the rate capability does not exhibit significant reduction for charging currents between $1 \mathrm{C}$ and $0.25 \mathrm{C}$, indicating the potentiality of perovskite-based materials for high power battery applications. Our findings reveal the outstanding electronic and ionic properties of lead halide perovskites, and their potential use as energy storage materials.

\section{Associated Content}

\section{Supporting Information}

Additional XPS spectra, and XRD analysis of lithiated and delithiated electrodes.

\section{Author Information.}

Corresponding author

*E-mail: garciag@uji.es

ORCID

Nuria Vicente: 0000-0002-9823-7131

Germà Garcia-Belmonte: 0000-0002-0172-6175

\section{Acknowledgments}

We thank financial support by Generalitat Valenciana under Prometeo Project (PROMETEO/2014/020), and Ministerio de Economía y Competitividad (MINECO) of Spain under Project (MAT2016-76892-C3-1-R). N.V. acknowledges University Jaume I through FPI Fellowship Program (PREDOC/2015/54). SCIC from Universitat Jaume I is also acknowledged. The authors acknowledge Celgard for supplying separator membranes.

\section{References}

(1) Kim, H.-S.; Lee, C.-R.; Im, J.-H.; Lee, K.-B.; Moehl, T.; Marchioro, A.; Moon, S.-J.; Humphry-Baker, R.; Yum, J.-H.; Moser, J. E.; et al. Lead Iodide Perovskite 
Sensitized All-Solid-State Submicron Thin Film Mesoscopic Solar Cell with Efficiency Exceeding 9\%. Sci. Rep. 2012, 2, 591.

(2) Liu, M.; Johnston, M. B.; Snaith, H. J. Efficient Planar Heterojunction Perovskite Solar Cells by Vapour Deposition. Nature 2013, 501, 395-398.

(3) Dou , L.; Yang, Y.; You, J.; Hong, Z.; Chang, W.-H.; Li, G.; Yang, Y. Solutionprocessed Hybrid Perovskite Photodetectors with High Detectivity. Nat. Commun. 2014, 5,5404 .

(4) Kim, Y.-H.; Cho, H.; Heo, J. H.; Kim, T.-S.; Myoung, N.; Lee, C.-L.; Im, S. H.; Lee, T.-W. Multicolored Organic/Inorganic Hybrid Perovskite Light-Emitting Diodes. Adv. Mater. 2015, 27, 1248.

(5) Suárez, I.; Juárez-Pérez, E. J.; Bisquert , J.; Mora-Seró, I.; Martínez-Pastor, J. P. Polymer/Perovskite Amplifying Waveguides for Active Hybrid Silicon Photonics. Adv. Mater. 2015, 27, 6157-6162.

(6) Deschler, F.; Price, M.; Pathak, S.; Klintberg, L. E.; Jarausch, D.-D.; Higler, R.; Hüttner, S.; Leijtens, T.; Stranks, S. D.; Snaith, H. J.; et al. High Photoluminescence Efficiency and Optically Pumped Lasing in Solution-Processed Mixed Halide Perovskite Semiconductors. J. Phys. Chem. Lett. 2014, 5, 1421-1426.

(7) Xing, G.; Mathews, N.; Lim, S. S.; Yantara, N.; Liu, X.; Sabba, D.; Gratzel, M.; Mhaisalkar, S.; Sum, T. C. Low-temperature Solution-processed Wavelength-tunable Perovskites for Lasing. Nat. Mater. 2014, 13, 476.

(8) Jiang, Q.; Chen, M.; Li, J.; Wang, M.; Zeng, X.; Besara, T.; Lu, J.; Xin, Y.; Shan, X.; Pan, B.; et al. Electrochemical Doping of Halide Perovskites with Ion Intercalation. ACS Nano 2017, 11, 1073-1079.

(9) Li, M.; Pietrowski, M. J.; De Souza, R. A.; Zhang, H.; Reaney, I. M.; Cook, S. N.; Kilner, J. A.; Sinclair, D. C. A Family of Oxide Ion Conductors Based on the Ferroelectric Perovskite $\mathrm{Na}_{0.5} \mathrm{Bi}_{0.5} \mathrm{TiO}_{3}$. Nat. Mater. 2014, 13, 31-35.

(10) Mizusaki, J.; Arai, K.; Fueki, K. Ionic Conduction of the Perovskite-type Halides. Solid State Ionics 1983, 11, 203-211.

(11) Xia, H.-R.; Sun, W.-T.; Peng, L.-M. Hydrothermal Synthesis of Organometal Halide Perovskites for Li-ion Batteries. Chem. Comm. 2015, 51, 13787-13790.

(12) Unge, E. L.; Hoke, E. T.; Bailie, C. D.; Nguyen, W. H.; Bowring, A. R.; Heumüller, T.; Christoforod, M. G.; McGehee, M. D. Hysteresis and Transient Behavior in Current-Voltage Measurements of Hybrid-Perovskite Absorber Solar Cells. Energy Environ. Sci. 2014, 7, 3690-3698.

(13) Zhang, W.; Eperon, G. E.; Snaith, H. J. Metal Halide Perovskites for Energy Applications. Nat. Energy 2016, 1, 16048.

(14) Haro, M.; Vicente, N.; Garcia-Belmonte, G. Oxygen Reduction Reaction 
Promotes $\mathrm{Li}^{+}$Desorption from Cathode Surface in Li-O2 Batteries. Adv. Mater. Interfaces 2015, 2, 1500369.

(15) Schmidt, L. C.; Pertegás, A.; González-Carrero, S.; Malinkiewicz, O.; Agouram, S.; Minguez Espallargas, G.; Bolink, H. J.; Galian, R. E.; Pérez-Prieto, J. Nontemplate Synthesis of $\mathrm{CH}_{3} \mathrm{NH}_{3} \mathrm{PbBr}_{3}$ Perovskite Nanoparticles. J. Am. Chem. Soc. 2014, 136, 850-853.

(16) Lindblad, R.; Jena, N. K.; Philippe, B.; Oscarsson, J.; Bi, D.; Lindblad, A.; Mandal, S.; Pal, B.; Sarma, D. D.; Karis, O. Electronic Structure of $\mathrm{CH}_{3} \mathrm{NH} 3 \mathrm{PbX} 3$ Perovskites: Dependence on the Halide Moiety. J. Phys. Chem. C 2015, 119, 18181825.

(17) Momose, H.; Honbo, H.; Takeuchi, S.; Nishimura, K.; Horiba, T.; Muranaka, Y.; Kozono, Y.; Miyadera, H. X-ray Photoelectron Spectroscopy Analyses of Lithium Intercalation and Alloying Reactions on Graphite Electrodes. J. Power Sources 1997, 68, 208-211.

(18) Zhang, Y.; Wang, Y.; Xu, Z.-Q.; Liu, J.; Song, J.; Xue, Y.; Wang, Z.; Zheng, J.; Jiang, L.; Zheng, C.; et al. Reversible Structural Swell-Shrink and Recoverable Optical Properties in Hybrid Inorganic-Organic Perovskite. ACS Nano 2016, 10, 7031-7038.

(19) Manser, J. S.; Christians, J. A.; Kamat, P. V. Intriguing Optoelectronic Properties of Metal Halide Perovskites. Chem. Rev. 2016, 116, 12956-13008.

(20) Miller, E. M.; Zhao, Y.; Mercado, C. C.; Saha, S. K.; Luther, J. M.; Zhu, K.; Stevanovic, V.; Perkins, C. L.; van de Lagemaat, J. Substrate-controlled band positions in $\mathrm{CH}_{3} \mathrm{NH}_{3} \mathrm{PbI}_{3}$ perovskite films. Phys. Chem. Chem. Phys. 2014, 16, 22122.

(21) Weber, D. $\mathrm{CH}_{3} \mathrm{NH}_{3} \mathrm{PbX}_{3}$, a $\mathrm{Pb}$ (II)-System with Cubic Perovskite Structure. $Z$. Naturforsch. 1978, 33b, 1443-1445.

(22) Zarazua, I.; Bisquert, J.; Garcia-Belmonte, G. Light-Induced Space-Charge Accumulation Zone as Photovoltaic Mechanism in Perovskite Solar Cells. J. Phys. Chem. Lett. 2016, 7, 525-528. 